\title{
ETHICAL DILEMMA IN THE PREGNANCY WITH FETAL MALFORMATIONS
}

\author{
Georgiana Russu', Radu Russu'

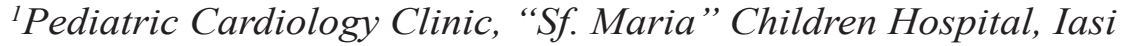 \\ ${ }^{2}$ Department of Pediatric Nephrology, "Sf. Maria" Children Hospital, Iasi
}

\begin{abstract}
Congenital heart malformations, with an incidence of $6-8 / 1,000$ births, represent about $30 \%$ of cases of infant mortality due to congenital abnormalities. Of these, most require immediate corrective surgery in the neonatal period. Kidney and urinary tract malformations have an incidence of approximately $1 \%$. The development of ultrasound techniques allowed for prenatal diagnosis of many fetal malformations, some of them lifethreatening. Thus, important ethical problems occur, concerning abortion or guidance of the pregnant woman to a center where the newborn will be operated in the first hours of life.
\end{abstract}

Keywords: ethical decisions, newborn, congenital heart defects, kidney malformations, fetal ultrasound

Congenital malformations are the main cause of death in infancy in industrialized countries. More than $55 \%$ of the major malformations can be detected by antenatal ultrasound. In the centers specialized in prenatal diagnosis, the detection rate by ultrasound performed at 11-14 weeks of pregnancy reaches 95\%. Neural tube malformations (hydrocephalus, myelomeningocele, anencephaly) have the highest rate of diagnosis $(92 \%)$, while the limb abnormalities, facial and genitourinary tract with the lowest detection rate (34\% each). Diagnostic percentage was also great for multiple malformations (60\%) (13).

Early detection of a congenital malformation determines controversy and specific ethical andmoral problems. It allows the clinician to provide appropriate advice to parents and take along a wellinformed decision to maintain or interrupt the pregnancy.

This radical gesture is indicated in severe malformations, incompatible with life, such as chromosomal abnormalities incompatible with longterm survival (trisomy 13, 18) and certain anatomical defects, especially of the brain (anencephaly) and kidneys (bilateral renal agenesis).
Caesarean premature delivery is indicated in the fetal malformations which determines dystocia or in the cases that require immediate surgical correction in a sterile environment (large omphalocele, severe hydrocephalus, ruptured myelomeningocelus, large sacrococcygeal teratoma).

Premature birth is indicated in maternal or fetal conditions in which the risk of continuation of the pregnancy for the function of the involved organ or system or for the viability of the fetus is greater than the risk of premature birth. Ideally, premature birth should take place in a center where there is the opportunity of immediate postnatal correction, to the benefit of the child (severe urinary tract obstruction, progressive hydrocephalus, intrauterine gradually growth retardation by disruption of the ombilical flow) (16).

Congenital heart diseases (CHD) are the most common birth defects, with a prevalence of $8 / 1,000$ newborns and causes nearly $50 \%$ of the cases of perinatal mortality and during the infancy. Fetal echocardiography was first reported by Winsberg in 1972 and proved to be a first-line diagnostic tool for screening children with CHD (18). 
Ultrasound screening for detection of abnormalities is recommended for all pregnant women between 18-20 weeks of pregnancy. If a CHD is suspected, the pregnant woman is referred to a center where fetal echocardiography will be performed by a pediatric cardiologist specialized and experienced, the detection rate being $100 \%$.

The incredible progress of modern medicine in recent years allow today a new therapeutic option in selected cases of fetal malformation-fetal surgery. This extremely invasive treatment has restricted indications: severe heart malformation (severe aortic stenosis with hypoplastic left heart syndrome, hypoplastic left ventricle already installed, with intact or highly restrictive interatrial septum, pulmonary artery atresia with intact interventricular septum or hypoplastic right heart syndrome), severe obstructive uropathy with bilateral hydronephrosis and oligohydramnios, severe evolutive hydrocephalus, severe pleural effusion which relapse after thoracentesis, syndrome of blood transfusion between twins (one being acardiac), amniotic bridge at risk for amputation of a limb, severe congenital diaphragmatic hernia with liver located intrathoracic, sacrococcigian teratoma (7). Intrauterine interventions determine many conflicts and debates between specialized international organizations, since the pregnant woman is in double role from the ethical point of view - a parent who must make a decision for the health of her future child, but also as a patient who decides for her own health. An intervention to the unborn child can be risky for pregnant woman, risks that she may not want to take. For example, administration of medications to the mother for treating fetal arrhythmias, or in utero surgical intervention for critical stenosis of aorta or pulmonary artery, improve the fetal prognosis, but it can cause premature birth or incising the mother's abdomen to facilitate access to the foetal heart (10).

Detection of renal anomalies through antenatal ultrasound was first reported in 1970 (2). Since then, the use of this method increased significantly, allowing early post-natal diagnosis of malformations and the adoption of a therapeutic attitude before the occurrence of clinical manifestations (urinary infection, pain, hematuria). Most cases of prenatal detected hydronephrosis do not impose special measures during pregnancy, only postnatal follow-up based on a well-established algorithm. However, it is essential informing the parents about the benign nature of many cases, requiring only postnatally follow-up, while others require medical or surgical treatment in specialized centers. The rare cases of severe bilateral renal malformations associated with oligohydramnios nowadays can be treated by surgery of vesico-amniotic shunt type. These programs of fetal treatment are carried out selective, in high performance centers, only for fetuses at risk of neonatal death (5). Fetal evaluation for structural anomalies performed during the ultrasound follow-up of the pregnancy has become a common practice in many countries, established itself as a screening method. In $1 \%$ of pregnancies a structural anomaly is identified by ultrasonography. About $20-50 \%$ of these abnormalities involve the genito-urinary system and $50 \%$ of these are manifested as hydronephrosis (15). Antenatal hydronephrosis is usually benign and transient, but may be the result of a pathological conditions that give rise to significant morbidity. Therefore, ultrasound monitoring of all pregnancies with fetus with hydronephrosis is recommended, with early involvement of a multidisciplinary team in order to establish as early as possible postnatal a plan of investigation and treatment to prevent the deterioration of renal function (19).

Fetal ultrasound provides valuable information for the obstetrician, neonatologist, genetician, pediatric surgeon, pediatric nephrologist, pediatric cardiologist, pediatric neurologist and neurosurgeon, multidisciplinary team involved in the care of a malformed child. If a malformation is detected, the rest of the pregnancy will be carried out in a climate of concern and anxiety for parents, the more accentuated with as malformation is more serious. In such cases, they must take a crucial decision that will inevitably affect them for the the rest of the life. The fetus is the passive side in these debates and decisions, and cannot say anything about his future and of the pregnancy. How are announced the unpleasant news and the way the diagnosis is explained influence a lot parents decision. With or without the involvement of a psychologist and other experts, at the end of the day the parents take the final decision themselves and should be supported, whatever it may be, otherwise they will bear an irreparable sense of guilt that will haunt them throughout the life (17).

Termination of pregnancy has been practiced from immemorial times in all cultures and civilizations, the indications and social context for this gesture varied, however, in relation to religion and moral principles of the time. Thus, infanticide was a frequent and accepted practice in the Greek and Roman society, who appreciated the strength, athletic appearance and everything they called male virtues. That's why they despised weak, dependent, 
immature children, that could not be useful to the State and society as future citizens (1). There were no laws to ban the killing of a ill or malformed newborn and it seems that most philosophers and writers of the time approved infanticide. Plato wrote in his work the Republic in the year 380 BC that infanticide is essential for maintaining the quality of the citizens: „Child of those inferior or of any other kind which was born with defects will be removed in secret, so that no one knows what have become". For Plato, the children were assessed according to the image of the ideal adult, they had to be ,malleable, virtuous, in good health and physically strong". Seneca, major stoic philosopher of the Roman Empire, wrote in his work About Anger in the year 41 BC: "Psych dogs beat them over the head; kill the fierce and wild ox; destroy unusual descendants; drown even children who are weak at birth and abnormal. However that's not anger, but the reason that separates noise from sound".

In contrast, the Hebrew community in the same period have a completely different attitude on newborns, derived from the Old Testament teachings, according to which every human being was made in the image of God (6). Therefore, every human being, healthy or deformed, slave or free man, was created with intrinsic value as unique expression of the image of God. The Old Testament laws stipulate that any destruction of human lives, including a newborn, was an affront to the dignity of God, and put a strong emphasis on the duty to protect the weak and helpless being assaulted. New Testament approved the terms of the Old Testament on infants and children and went away, Jesus preached the importance of children, who have a particular feeling (11).

Basic ethical principles in the care of a malformed fetus pregnancies were eloquently described Chervenak et al (3). The first principle is the benefit of the patient and the second is to respect patient autonomy. The doctor must respect the decision capacity of the patient's way of thinking and scale of values, but provides more complete information on the condition and treatment plan, explaining parenthood what is still uncertain, unclear or that may change as pregnancy advances. One must not forget the possibility of association of congenital heart or kidney malformation with malformations of other organs or chromosomal abnormalities. It is vital that the information is provided so that the patient understands, in order to make an informed and voluntary decision. But it is essential to take into account the high degree of stress of the future parents and the shock that can follow the comunicati- on of a severe diagnosis, which influence their ability to understand and assimilate the information provided, even if presented with great care.

The decision to continue or end a pregnancy complicated by fetal abnormalities is extremely difficult, especially when it associates abnormalities with unpredictable or highly variable clinical expression. Kuppermann et al studied the response to prenatal testing and abortion of parents of children with intellectual disabilities. Many such couples seeking further information about the fetus and other future pregnancies, but most oppose abortion (9).

The major ethical problem in the pregnancy complicated by fetal malformations is if the fetus is considered independent as a patient entitled to clinical benefit in addition to the pregnant woman. If so, then the ethic situation becomes much more complex, as the best option for pregnant may not be best for the child (eg if continuation of pregnancy is risky for the life of the pregnant woman). In addition, the women may take a decision contrary to the interests of the fetus (ie terminating a pregnancy with a viable fetus). Many authors $(8,14)$ believe that the fetus is not a person with rights, not having values and beliefs, but the right to the clinical benefit will be received immediately after birth, making the fetus to be a patient, whether regarded as a person or not. Moreover, Chervenak argues that the fetus becomes a patient only if he is viable, the previable fetus does not have the status of the patient, unless his mother wants him to be regarded as such. Once it is viable and can survive independently outside the womb he gets right to the clinical benefit and the doctor is obliged to make the right decision that will not affect adversely his evolution and development as infant, child or adult.

If this argument is accepted, the doctor is required to amend or even ignore the woman's decision, for the sake of the fetus, which he treates like any other patient. If the decision of the pregnant woman is contrary to the interests of the child that the fetus will turn on, then the doctor has the obligation to protect those interests, as for any other child endangered by the parental choice regarding the medical treatment. Therefore, if the attempt of conviction is not successful, then the doctor should seek legal ways that violate woman's decision, which may result in fetal surgery, inducing birth or ongoing pregnancy by court (12).

Basic ethical principles, the respect of the autonomy and the benefit play the main role in the ethical responsibilities of the doctor that takes care of a pregnancy with possible malformed fetus. Major 
ethical obligation of the physician is to provide accurate information in a manner that takes into account the stress of the parents, so they can make the right decision. The ethical principle of autonomy requires the doctor to help the pregnant woman to make an informed decision according to her own values and aspirations, according to legal, cultural and religious constraints. The decision to interrupt the pregnancy is complicated by the fact that there are very few defects which can not be corrected surgically with satisfactory quality of life further. Parents are struggling so greyscale. In addition, the new option of fetal intervention emerged, increasingly used in developed countries with centers of excellence, which can be useful for fetal / infant / child, but it can be risky for the mother, who can refuse this option. Overall, the main message is correct and complete information of the parents about the diagnosis, prognosis and treatment of existing malformations, and discussing options and potential complications which may occur to the fetus and pregnant mother.

\section{REFERENCES}

1. Amundsen D.W. Medicine and the birth of defective children, approaches of the ancient world. In McMillan RC, Engelhardt HT, Spiker SF (eds): Euthanasia and the newborn. Dordrecht: D. Reidel 1987: 3-22.

2. Caiulo V.A., Caiulo S., Gargasole C., Chiriacò G., Latini G., Cataldi L., Mele G. Ultrasound mass screening for congenital anomalies of the kidney and urinary tract, Pediatr Nephrol. 27(6) 2012, 949.

3. Chervenak F.A., McCullough L.B., Skupski D., Chasen S.T. Ethical issues in the management of pregnancies complicated by fetal anomalies, Obs Gynecol Survey 58(7), 2003, 473-483.

4. Codul Penal - Legea nr.286/2009, Partea II, Titlul I, Capitolul IV Agresiuni asupra fătului, Art. 201 - Întreruperea cursului sarcinii.

5. Fefer S., Ellsworth P. Prenatal Hydronephrosis, Pediatr Clin N Am 53, 2006, 429-427.

6. Geneza 1:27.

7. Kalish B.T., Tworetzky W. Fetal cardiac interventions, in Da Cruz EM, Ivy D, Jaggers J (eds): Pediatric and congenital cardiology, cardiac surgery and intensive surgery, Springer-Verlag London 2014, 293-300.

8. Kowalcek I. Stress and anxiety associated with prenatal diagnosis, Clin Obstetr Gynaecol 21 (2), 2007, 221-228.

9. Kuppermann M., Nakagawa S., Cohen S.R., et al. Attitudes toward prenatal testing and pregnancy termination among a diverse population of parents of children with intellectual disabilities. Prenat Diagn. 2011; 31(13):1251-8.

10. Malhotra A., Menahem S., Gillam L. Ethical issues in fetal management: a cardiac perspective, Intern J Pediatr 2010 (2010), 857460 .

11. Matei 19: 13-16.

12. Orentlicher D., Halkola K. Legal interventions during pregnancy. Court-ordered medical treatments and legal penalties for potentially harmful behaviour by pregnant woman, JAMA 264 (20), 1990, 2663-2670.

13. Rossi A.C., Prefumo F. Accuracy of ultrasonography at 11-14 weeks of gestation for detection of fetal structural anomalies: a systematic review. Obstet Gynecol. 122(6), Dec 2013, 1160-7.

14. Shinebourne E.A. Termination, consent and innovation: ethical and legal aspects of paediatric cardiology, Cardiol Young 8 (4), 1998, 428-436.

15. Sidhu G., Beyene J., Rosenblum N. Outcome of isolated antenatal hydronephrosis: a systematic review and meta-analysis, Pediatr Nephrol 21, 2006, 218-224.

16. Springer S.T. Prenatal diagnosis and fetal therapy, 12 decembrie 2013. Available at http://www.emedicine.com/viewarticle 936318.

17. Uzun O. Ethical dilemmas in fetal cardiology: improving outcome or reducing incidence, Welsh Paed J 28, 2008, 7-12.

18. Winsberg F. Echocardiography of the fetal and newborn heart, Invest Radiol 7, 1972, 152.

19. Westera J., Lambrianides A.L., Meyer J.P. The management of antenatal hydronephrosis detected on routine prenatal ultrasound, J Clin Urol published online 18 March 2013. 